\title{
Research of Chengdu modern industrial architectural heritage
}

\author{
Li-Yang Lu and Yun-Zhang $\mathrm{Li}^{\mathrm{a}}$ \\ College of Architecture and Environment, Sichuan University, Chengdu 610065, China
}

\begin{abstract}
It is industry, fruit of civilization, symbolizes the progress of the society of human beings. The industrial architectural heritage is an important part of the culture and signals the advance of the science and technology in the industry. The developing process of modern industry in Chengdu highlights the manufacturing progress in Sichuan even the inland China. With the development of the cities, the upgrade, the relocation and reconstruction of the enterprises, protecting the industrial architectural heritage has become a major case on the studying of the progressing procedure of manufacturing. A good conservation and reuse on the heritage will promote the economy and culture in the region. The article systematically elaborates the history of modern industrial development in Chengdu, summarizes the existing types of the architectural heritage in the industry; analyzes the layout, spatial form, styles; presents two representative industrial architectural heritage and a reformation area; points out current situation the heritage sits in and the protection measures on it, as well as its limitations and some related suggestion.
\end{abstract}

\section{Introduction}

In 1840, the Opium War broke out, which made China step into the Modern History stage. Under the promotion of Self-Strengthening Movement, the Qing government established a number of modern military and civil industries in 1861[1], which opened the gate of Chinese modern industry.

But Chengdu, located in the hinterland of Western Sichuan Plain, was under the economic limit for geographical factors. All this delayed the development speed of modern industry in Chengdu.

The opening of Chongqing port in 1890 enhanced the formation and development of the commodity market in Chengdu. Due to years of battle between feudal warlords, the modern industry of Chengdu, even Sichuan, lagged behind the port cities hugely.

Many port cities fall to Japan's control since China's Anti-Japanese War which began on July 7, 1937. In order to ensure material demand, 155 factories were selected to move into Sichuan.

Chengdu's modern industry went into a surging period, but the development speed of its heavy industry was remained at a slow speed. Speaking of the shipping conditions, Chengdu was next to close-range Chongqing. After then-government relocated its capital to Chongqing, the city became the only comprehensive industrial base of China. Its hilly terrain helps conceal factories, facilities and munitions during wartime[2]. After the war, most of the factories returned to the cities where they used to locate in.

\footnotetext{
${ }^{\mathrm{a}}$ Corresponding author : 307941240@qq.com
} 
At the time, Chengdu's economy suffered from inflation and repression from then-government-run industries, coupled with the proliferation of foreign goods. The industrial output of Chengdu was only 108 million yuan before 1949, in which the handicraft counted 14,000 households, making up 98.8\% of the sum. Few contributions were made by modern industry to Chengdu's economy[3].

In 1953, Chengdu was included as one of the eight national key cities. Nine industrial infrastructural projects were settled in Chengdu, with 4 electronics industries centralized in Eastern Suburbs of Chengdu. In 1955, the State Council formally approved the East Suburb of Chengdu as one of the three national electronic industrial base.

In 1964, the main task was to re-planning and rebuilding modern industry, known as the Third Front Movement plan. As the commanding center of Third Front Movement in Southwest China, Chengdu completed a thorough transformation from consumer-oriented city to an industrial-oriented city[4].

\section{Characteristic of industrial architectural heritage in Chengdu}

\subsection{Type}

Before the liberation of the country, Chengdu's economy was dominated by the specialization of workshops and manufacturing rather than steam engine-powered modern industry. The production methods and operating models of the specialization of workshops and manufacturing didn't bring the modern industrial buildings.

\subsection{Layout}

The modern industry in the West was reformed from traditional handicraft and manufacture. The modern industry of Chengdu, which was roughly copied from the West at the beginning, undermined the natural transition from local manufacturing. It resulted in a shaky foundation and misdistribution for the industry[5]. But as a result of unified planning and construction after 1949, the layout of Chengdu's industrial plants was concentrated.

Chengdu's plain terrain is conducive to productive activities. It offers open space which is beneficial to achieve structure and production activities. The buildings of plant arranged horizontally or longitudinally. The plan of one single block was also neat and simple.

\subsection{Space form}

Not only a large number of production buildings, factories and warehouses, but also production-assist buildings, such as office buildings and dormitories exist in industrial plants for the multifunction involving production, dwelling and management.

The high green coverage rate could cut down the pollution of production and living to a minimum and prevent the damage to the workers' health. Furthermore, the folks are accustomed to housing pattern in courtyard. High green rate reaps huge fruits in improving micro-climate, cleaning air and reducing noise, ameliorating working and dwelling conditions.

Production buildings take steel structure or reinforced concrete structure. In order to ensure the access of the equipment for lifting and transporting, an open interior is needed. Diverse functions, connected with each other, can be found in one block, sharing the flexible designing on the floor height. Side-windows and skylights, designed for demanding illumination condition, constitute a rich form of profiles.

Production-assist buildings use brick and concrete structure. The sense of efficient space using calls for internal corridors. And the increasing thought of electric light, fire code, demanding mechanical smoke extraction, forms the prototype of the modern public buildings. 


\subsection{Features}

In the 1930s, the trend of modern Western architecture began to affect the trends of Chinese architecture. In the 1950s, the Soviet Union aided China 156 key projects, which brought in the Soviet socialist principle.

The principle urges buildings with sound functionality, reasonable budget and ideological consideration, "reflecting the greatness and beauty of socialism," Si-Cheng Liang noted "in the form of national "as the interpretation of Soviet socialism[6].

Architects were attempting to combine the traditional style with western style. Under the prevailing economic background and the assimilation of western building thoughts, the image of Chengdu industrial buildings suggests three primary characteristics:

(1) Significantly modern features, no decorations, no ornaments, were built to ensure production activities;

(2) Layout, facade designing, materials take the form of Russian (European) style, with some traditional Chinese elements in certain details;

(3) Traditional Chinese architectural elements were used (especially for the roofs), a modern structure, regardless of traditional scale, combined with the European symbols.

\section{Case analysis}

\subsection{Chengdu measuring \& cutting tool factory building}

Chengdu Measuring \& Cutting Tool Factory, built in 1956, was a key enterprise of in measuring and cutting instruments for New China.

The building was used as offices and workshops. Its structure as well as its outer wall was in imitation of the Harbin Measuring \& Cutting Tool Factory building. The building faces northwest, sits straight along Fuqing Road. Brick and concrete structure with total width, depth and gross floor area reach $20.31 \mathrm{~m}, 19.45 \mathrm{~m}$ and $11748.96 \mathrm{~m} 2$. Exterior walls consist of red bricks, while beams and columns are made of reinforced concrete and precast reinforced concrete panels floors. The outer wall was painted beige at first, then changed to red in 1990 as shown in Figure 1.
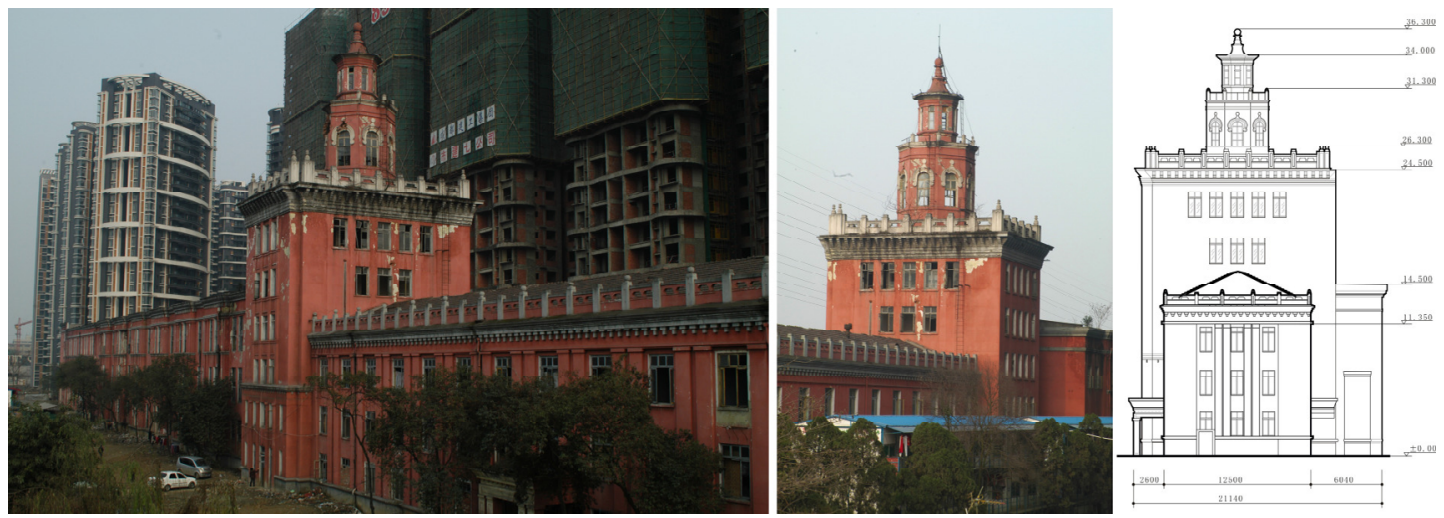

Figure 1. Chengdu Measuring \& Cutting Tool Factory building and the right side elevation.

Followed the classical composition form of European buildings, the landscape and portrait of the building are three-patterned, substantially symmetrical layout, the middle six-storey (partial eightstorey) with a vase top and arched windows on each side.

The southern part of the block consists of three-storey offices, mechanism red tile roof with fences on the cornices. The northern part of the block features three-storey workshops with higher floor height, flat roof with parapets on its upper side. The farthest part is work cabins and lounge. Eight asymmetrical stairs were arranged according to their different functions. 
The designer balanced aesthetics with practicability to ensure the efficiency of project funding. It achieves a good visual effect by using traditional elements on the roofs, eaves and railings. The Figure 2 shows the ground floor plan and Positive elevation of Chengdu Measuring \& Cutting Tool Factory building.
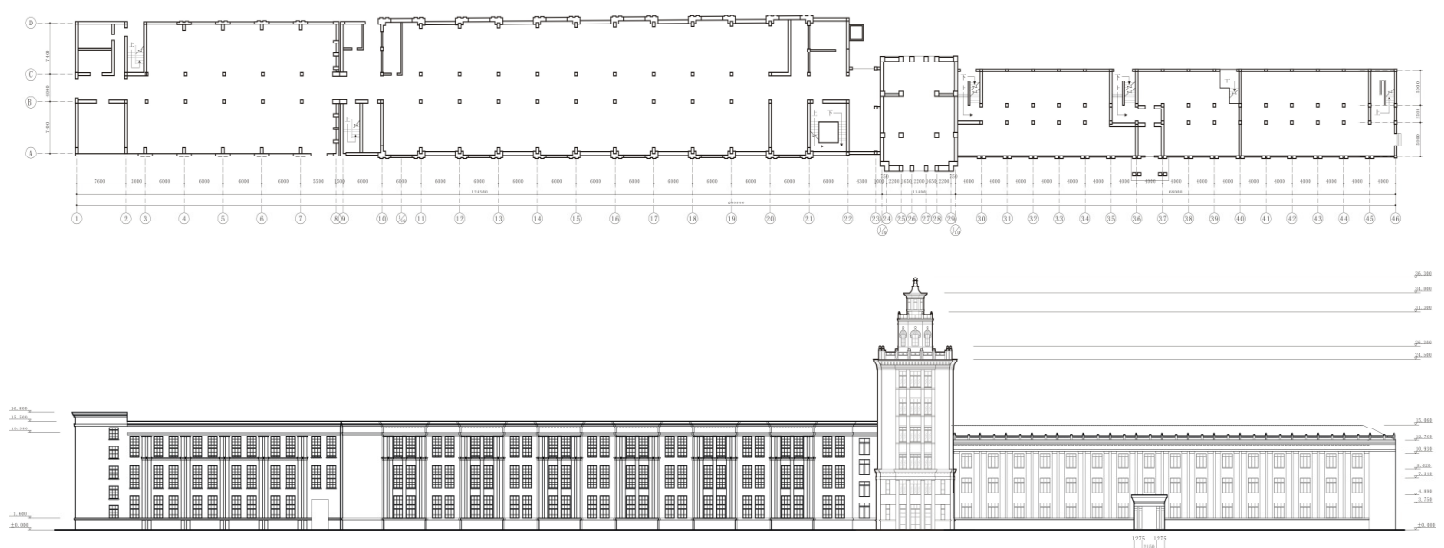

Figure 2. Ground floor plan and Positive elevation of Chengdu Measuring \& Cutting Tool Factory building.

\subsection{Chengdu vehicle factory building}

Founded in 1952, Chengdu Vehicle Factory was a large state-owned enterprise, which is Top 500 of China's transportation equipment and railway vehicle company.

Chengdu Vehicle Factory building is a two-storey Soviet-style building, sits from northeast to southwest, covered an area of $693 \mathrm{~m}^{2}$. It is made of brick and wood, shapes like a reversed letter T. Its length, width and height are $42 \mathrm{~m}, 14 \mathrm{~m}$ and $14.6 \mathrm{~m}$, with the single-storey bulge $9.5 \mathrm{~m}$ in length and $11 \mathrm{~m}$ in width.

The base of black brick walls is surfaced with wipe terrazzo. Walls support beams and hip roof covers small tiles. The northeast part of the building forming a square balcony up there with decorative sculptures. A wooden door with frame carved patterns is at the end of the central corridor. Middle part of the building lays a cement staircase to the second floor. Both southeast and northwest sides of the building have two small balconies. The Figure 3 shows the ground floor plan, as well as the status photos of Chengdu Vehicle Factory building.

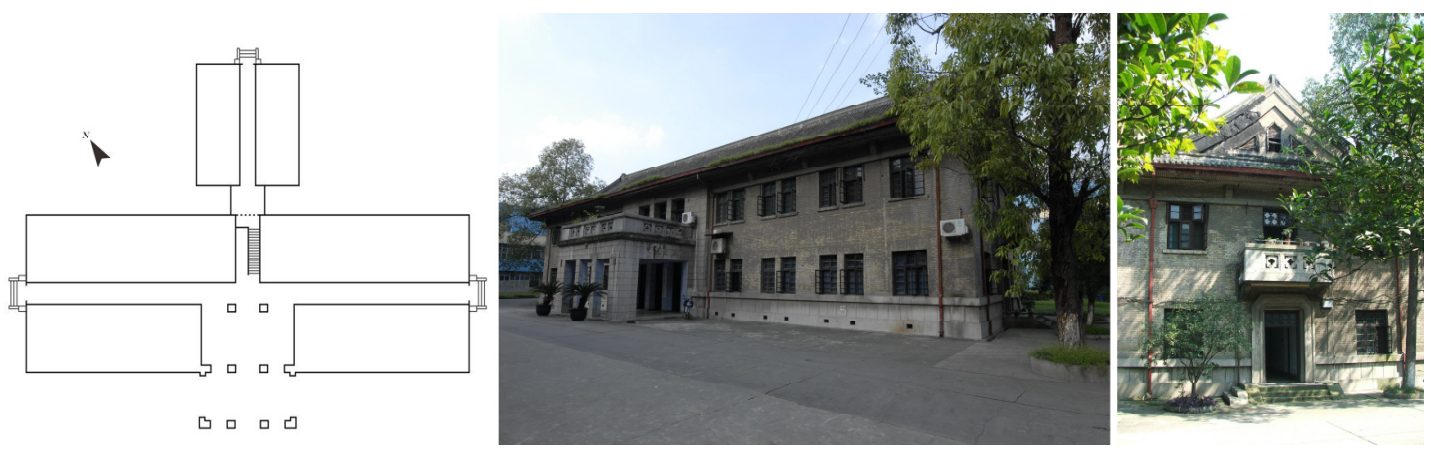

Figure 3. Ground floor plan, the main entrance and side entrance of Chengdu Vehicle Factory building.

Chengdu Vehicle Factory building is used as the vehicle-checking room of the Ministry of Railways in Chengdu. 


\subsection{Chengdu memory of eastern suburbs}

Chengdu Memory of Eastern Suburbs transformed from Red-light Factory which was one of 156 major projects aided by the Soviet Union. It was put into operation in November 1958, known for the base of electric device and birthplace of domestic television tube. Chengdu Memory of Eastern Suburbs consists of tube-assemble workshop, fitter workshop, infrastructure division office, warehouse, cylinder workshop, gas-production workshop, material-assemble workshop, indicatorassemble workshop, processing workshop and factory building, which are shown in the Figure 4.

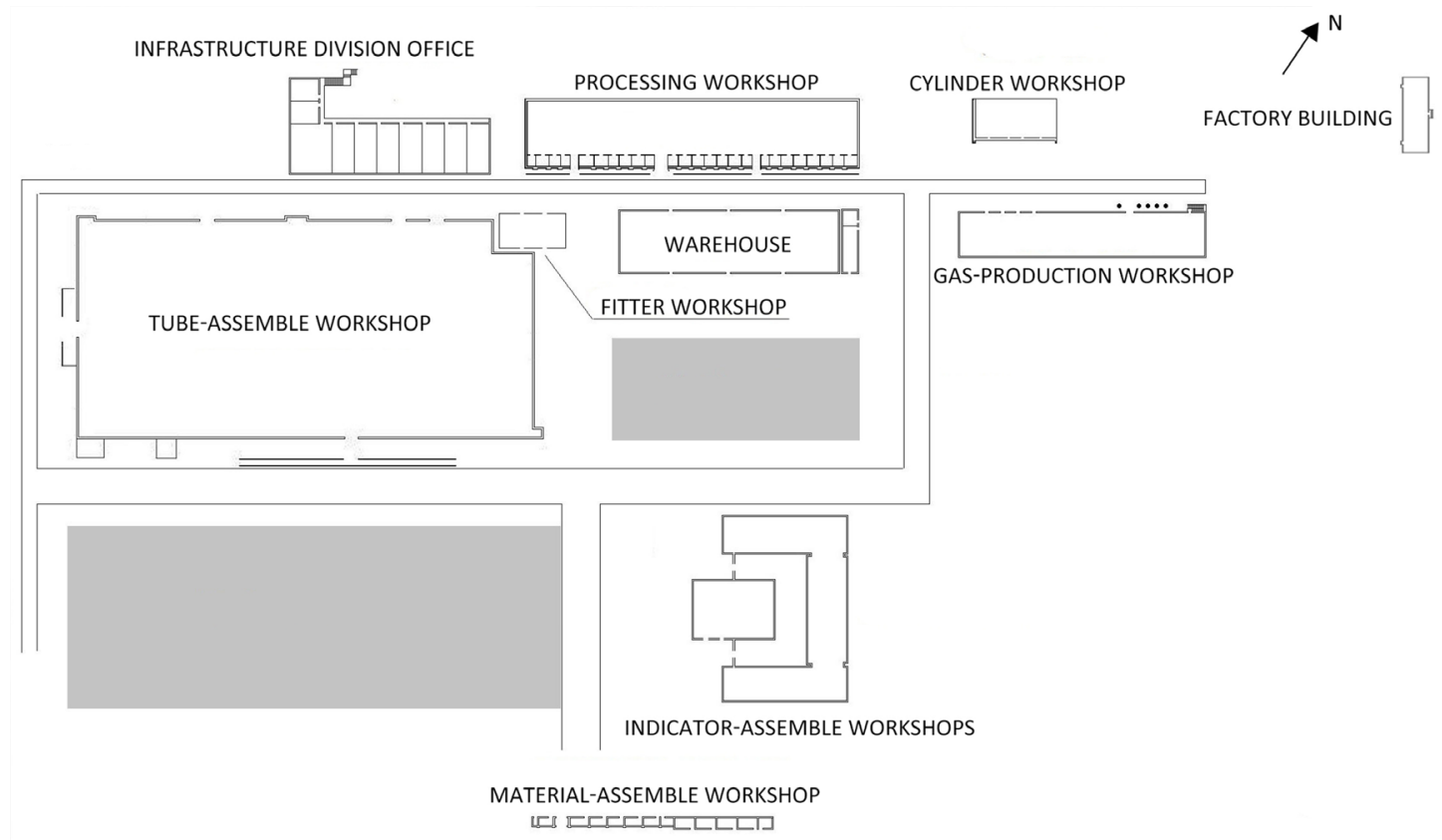

Figure 4. Ground floor plan of Red-light Factory.

Tube-assemble workshop faces southwest, single-layer, flat-topped, brick wall covering with lime, $187 \mathrm{~m}$ in length, $100 \mathrm{~m}$ in width, $9 \mathrm{~m}$ in height, covers an area of $18700 \mathrm{~m}^{2}$.

The two indicator-assemble workshops cover an area of $6072 \mathrm{~m}^{2}$. The layout of the two is 凸shaped. The first one is a four-storey building with flat roof, symmetrically 凹-shaped, reinforced concrete structure, $92 \mathrm{~m}$ in length, $34 \mathrm{~m}$ in width, $21 \mathrm{~m}$ in height. Another one is located inside the former one, with a rectangular layout, $66 \mathrm{~m}$ in length, $28 \mathrm{~m}$ in width, $22.5 \mathrm{~m}$ in height.

The factory building is on a three-storey reinforced concrete structure with a flat top. The whole building is symmetrically arranged by the middle main entrance, $100 \mathrm{~m}$ in length, $16 \mathrm{~m}$ in width, $14 \mathrm{~m}$ in height.

\section{Protection of industrial architectural heritage in Chengdu}

\subsection{Current situation}

Since 1990, a few cities stepped into the post-industrial period gradually. Under the guidance of macroeconomic policy obeying socialist market economy, the traditional industrial structure of Chengdu started to change. 
The 1998 edition city plan considered Chengdu as a modern city for losing its historical and cultural characteristics, which resulted in ignoring the protection of modern architecture which out of the conventional category of cultural relics[7].

In June 1, 2007, modern industrial architectural heritage, for the first time, was listed in the Seventh Batch of Provincial-level Protective Cultural Relics announced by Sichuan Provincial Government.

In July 16, 2012, the Eighth Batch of Provincial-level Protective Cultural Relics indicated a significant increase in the proportion. It was a meaningful expansion and extension of relic category.

\subsection{Protection legislation}

In 2004, Chengdu revised the city plan, pinned the city as a historical and cultural one, putting forward the requirements of heritage protection explicitly. In July 28, 2005, Planning Administration of Chengdu leaded to compile the protective outline. According to the guidance on Strengthening the Protection of Excellent Modern Architecture published by the Ministry of Construction, Protection Planning of Chengdu Excellent Modern Architecture took effect by the end of 2005, including quite a few industrial architectural heritage.

\subsection{Protection method}

\subsubsection{Reconstruction into museum}

The reconstruction of the heritage into a museum is a crucial protective way to preserve the modern industrial architecture.

Eastern Suburbs of Chengdu Industrial Civilization Museum, reconstructed by repairing workshops of Hongming Machine Factory, is the first classic case of reconstructing industrial plants to a theme museum, which highlights the industrial process of Eastern Suburbs of Chengdu from the 1950 s to the 1980 s.

\subsubsection{Renovation into public service}

Designed to provide or assist in production, each building can be renovated into public service in social life after the closure of industrial activities.

Located at the intersection of North Road and Second Ring Road, Yudong Shikong Badminton Arena is reconstructed based on producing workshops of Electric Welder Machine Factory. On account of lacking in sports areas and facilities nearby, the badminton arena provides convenience for folks around.

\subsubsection{Updating into cultural industrial zone}

Cultural industrial zone is a vivid revelation of the past and retain the urban history to some extent, as well as being beneficial to enhance the updating of obsolete urban district to stimulate regional vitality and creativity.

After the industry adjustment of Eastern Suburbs of Chengdu, Chengdu Memory of Eastern Suburbs grew from the Red-light Factory. Located on a 218 acre land parcels, the park has become the largest industrial updating project in southwest with the gross floor area accounting for 189,000 square meters. The original of about 14 million square meters of plants are remained, which give full play to regional integration and aggregation efficiency, becoming the first digital music-themed park of China. The Figure 5 shows the state of the Chengdu Memory of Eastern Suburbs. 

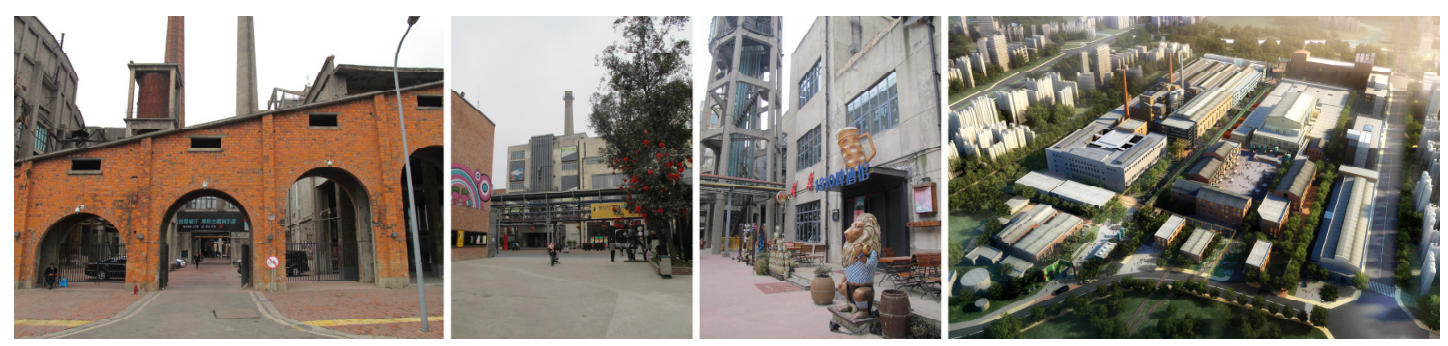

Figure 5. Chengdu Memory of Eastern Suburbs.

\section{Conclusion}

Eastern Suburbs of Chengdu is the centre for modern industrial architectural heritage with abundant facilities full of strong historic culture. Besides a minority of industrial buildings scattered or far away from the urban area are on the fringe of the effective protection. Due to the lax of protection awareness when comparing with the urban planning and construction, the industrial architectural heritage on the fringes, isolated by the tremendous changed urban framework, is at risk. Moreover, the reconstruction and the renovation are also limited by modern environment.

Located on the 31st, Sanguantang Street, the watchtower is the heritage of Self-Strengthening Movement. Being one of the four watchtowers built in 1878 and owned by Sichuan Machinery Bureau, the surviving one has been beleaguered by advertisement and garbage one year after being cataloged in the First Batch of Excellent Modern Architecture in Chengdu. The deficiency of relevant data and information, limited by the geographical factors and uncertainty, caused by the complicated historical background, industrial architectural heritage on the fringes is often ignored when having cultural relics survey. After the closure of production activities, some of these were wiped out[8].

The Nanbao forge, built in 1958, is a historical relic of Great Leap Forward movement, provides visible data of iron smelting technology. Only one of the original more-than-10 survives.The protection of industrial architectural heritages requires industrial diversity, the echelon of the dates and the variety of its types. Only when fulfilled all these can we complete the history of modern industrial development.

While domestic protection focuses on the preservation of buildings and the facilities, production process, interaction between residents and environment, local memory, technological innovation and major events, all mentioned above has not been particularly presented. The spatiality is the basic assets of industrial heritage, while the meaning and memory it represents is the potential cultural assets indeed. The profound emotion and intimate connection between buildings and people consists of unique history each block on behalf of. The emotional awareness could evolve into protection consciousness. Only after pouring attention into cultural assets to stimulate the sense of involvement and historical identity can we have the industrial architectural heritage being well-preserved and the history of Chengdu modern industry and the process of modern architecture development can pass down for long generations.

\section{References}

1. H.M. Chen, Geographical distribution and influence of Chinese modern industry (1927-1861), Economic Research Guide, 15, 63-65 (2013)

2. D.F. $\mathrm{Xu}$, The chongqing industrial heritage conservation reuse and urban revitalization, $\mathrm{PhD}$ Thesis, Chongqing University, China (2012)

3. W. Zhong, From "three and a half chimney" to leading the economic development of western industrial -- Chengdu industrial development, Chengdu Daily, T63 (2011) 
4. X.Z. Li, The 60 years of chengdu: from third front movement to urban-rural integration, China Business News, 23 (2009)

5. H.Y. Liu and Z.F. Wang, The unique way to the formation and development of China's modern industry, Journal of Jiangsu Normal University(Philosophy and Social Sciences Edition), 1, 21-24 (1996)

6. G.H. Ji, Architecture of New China and the Soviet Union- import of Soviet architectural theory and impact on China in 1950s, Cities and Towns Construction in Guangxi, 2, 70-74 (2013)

7. B.Y. Liu, A review of industrial architecture heritage research in China, New Architecture (2012)

8. X.Y. Chen, Reuse of industrial buildings, Sichuan Building Science, 39, 271-274 (2013) 